Relations industrielles

Industrial Relations

\title{
Labor Relations Law, 3rd edition, by B.J. Taylor and F. Witney, Prentice-Hall, Inc., 1979, 834 pp.
}

Rodrigue Blouin

Volume 35, numéro 1, 1980

URI : https://id.erudit.org/iderudit/029055ar

DOI : https://doi.org/10.7202/029055ar

Aller au sommaire du numéro

Éditeur(s)

Département des relations industrielles de l'Université Laval

ISSN

0034-379X (imprimé)

1703-8138 (numérique)

Découvrir la revue

Citer ce compte rendu

Blouin, R. (1980). Compte rendu de [Labor Relations Law, 3rd edition, by B.J.

Taylor and F. Witney, Prentice-Hall, Inc., 1979, 834 pp.] Relations industrielles /

Industrial Relations, 35(1), 175-175. https://doi.org/10.7202/029055ar

Tous droits réservés @ C Département des relations industrielles de l'Université Laval, 1980
Ce document est protégé par la loi sur le droit d'auteur. L'utilisation des services d'Érudit (y compris la reproduction) est assujettie à sa politique d'utilisation que vous pouvez consulter en ligne.

https://apropos.erudit.org/fr/usagers/politique-dutilisation/ 
section du livre de Page Arnot raconte la présentation du Bill au Parlement de 1945 à 1946. Son récit est fondé presque entièrement sur des extraits d'Hansard et n'ajoute rien aux détails connus. Mais l'un des arguments favoris des conservateurs allait prendre une signification ironique. "Vous n'allez que remplacer un groupe de patrons par un autre», - disaient-ils en se moquant des députés mineurs, "et choisir un patron plus éloigné et plus fort - l'état». L'avenir allait révéler la force de cette observation, et aussi sa faiblesse.

\section{Trevor BURRIDGE}

Université de Montréal

Labor Relations Law, 3rd edition, by B.J. Taylor and F. Witney, Prentice-Hall, Inc., 1979, 834 pp.

Fidele aux éditions antérieures, cet ouvrage n'en est pas un strictement juridique. Les auteurs étudient en effet, plus exactement présentent l'ordonnancement légal régissant la négociation collective aux États-Unis en le remplaçant dans son environnement. Le juriste comme le non-juriste peut donc encore trouver un intérêt certain dans ce véritable traité.

La structure de présentation n'a pas été modifiée. Ainsi, en dépit des six grands thèmes qui retiennent toujours l'attention, il nous semble que les auteurs privilégient trois axes fondamentaux dans l'évolution. Les premiers propos, qui comportent des données de mise en contexte, couvrent la période des origines jusqu'au Wagner Act (i: Introduction to Collective Agreement; ii: Legal Suppression of Collective Agreement; iii: Governement Encouragement to Collective Bargaining). Par la suite, le lecteur se voit offrir une revue des principaux événements en- tourant l'adoption et les lendemains du TaftHartley Act (iv: Control of Collective Bargaining; Collective bargaining: Area of Industrial Conflict). Finalement, il est question du Lendrum-Griffin Act jusqu'à nos jours (vi: Additional Areas of Government Control).

Si l'on fait exception d'un nouveau chapitre consacré à la discrimination dans l'emploi, incidemment des plus intéressant, le contenu n'a pas été substantiellement modifié. En fait, il s'agit d'une mise à jour où les auteurs font bien ressortir les nouvelles approches retenues en jurisprudence. On notera une exception; l'étude des relations du travail dans le secteur public, notamment dans les hôpitaux, a été à peu de chose près complètement reprise. Nous signalons la présentation des programmes de refonte du président Carter et des problèmes encourus. Notons finalement en fin du volume la reproduction des huit (8) principales lois américaines en la matière.

De façon générale, cet ouvrage conserve la qualité de ses prédécesseurs: clarté et concision. On notera que les auteurs ont fait un effort certain pour expliquer davantage les coûts de la négociation collective, des politiques publiques en relations du travail, de la "socio-economic rationale" des pièces législatives. Le but recherché semble d'amener le lecteur à mieux évaluer le système. La démarche peut susciter la réflexion.

Cet ouvrage mérite d'être parcouru et constitue indéniablement un instrument de réflexion qui doit se retrouver en bibliothèque.

Rodrigue BLOUIN

Université Laval 